\title{
Antifreezing ionotronic skin based on flexible, transparent, and tunable ionic conductive nanocellulose hydrogels
}

\section{Enwen Zhu}

Wuhan University of Technology

Haiyu Xu

Wuhan University of Technology

\section{Yuanyuan Xie}

Wuhan University of Technology

\section{Yiheng Song}

Wuhan University of Technology - Mafangshan Campus: Wuhan University of Technology

\section{Dongning Liu}

Wuhan University of Technology

\section{Yujiao Gao}

Wuhan University of technology

\section{Zhuqun Shi ( $\nabla$ zqshi2016@whut.edu.cn )}

"Wuhan University of Technology"

\section{Quanling Yang}

Wuhan University of Technology

Chuanxi Xiong

Wuhan University of Technology

\section{Research Article}

Keywords: Ionotronic skin, Nanocellulose, Antifreezing, Sensing properties

Posted Date: March 15th, 2021

DOI: https://doi.org/10.21203/rs.3.rs-301919/v1

License: (c) (1) This work is licensed under a Creative Commons Attribution 4.0 International License. Read Full License 


\section{Abstract}

lonic hydrogels with excellent flexibility and good conductivity have great potential in diverse electric devices. However, it remains challenging to improve the biocompatibility of ionic hydrogels. Here, natural and environment-friendly cellulose nanofiber hydrogels were prepared without adding any organic active materials. The cellulose hydrogel networks with free metal ions $\left(\mathrm{Li}^{+} / \mathrm{Ca}^{2+} / \mathrm{K}^{+}\right)$were obtained by soaking in ion aqueous solution of different concentrations in order to endow tunable conductivity, thus a new kind of transparent ionic hydrogels with both excellent sensing performance obtained by a simple, lowcost and harmless process. The free metal ions locked in the negatively charged nanocellulose network through electrostatic interaction provided adjustable conductivity and sensing performance. Hydrogels doped with $4 \mathrm{~mol} \mathrm{~L}^{-1}$ lithium ions exhibited the best sensing performance with the conductivity of $4.36 \times 10^{-4} \mathrm{~S} \mathrm{~cm}^{-1}$, and the current response value was as high as $127 \%$. It was worth noting that the strain-sensitive performance of calcium ions was generally excellent even at low temperatures $\left(-30^{\circ} \mathrm{C}\right)$. The antifreezing of the hydrogel improved its service under extreme environment. This kind of hydrogel has great application prospects in artificial intelligence products, such as human healthy monitoring equipment and soft robotics at subzero temperature.

\section{Introduction}

Retractable, wearable (Darabi et al. 2017), flexible strain sensors (Huang et al. 2018) are widely used in the field of electronic devices (Amjadi et al. 2016), such as health monitoring (Wan et al. 2017), humancomputer interaction (Zhao et al. 2017). Capacitive sensor (Xu et al. 2020; Tao et al. 2017) and piezoresistive sensor (Kwon et al. 2016) present advantages of simple device construction and higher sensitivity (Song et al. 2020; Wang et al. 2014; Qiu et al. 2018; Lin et al. 2016). Sun and co-workers first proposed the concept of ionic skin and used polyacrylamide hydrogel as the ionic conductor, which could be stretched to about six times and the capacitance of the sensor changed as strain (Sun et al. 2019; Yan et al. 2014). Conductive hydrogels (Cao et al. 2020) are concerned as a promising material for ionic skin and bio-sensors due to their hydrophilicity. Flexible strain sensors were required to have good mechanical properties and high conductivity. Ding and co-workers described a novel type of transparent ionic gel with a conductivity of up to $2.4 \mathrm{~S} \mathrm{~m}^{-1}$ by locking a free ionic liquid into a charged poly (2-acrylamido-2-methyl1-propanesulfonic acid) (PAMPS)-based double networks (Ding et al. 2017). Cai and co-workers designed a hydrogel with excellent mechanical properties, which can withstand strains of up to $1000 \%$. It was a stretchable self-healing varistor strain sensor made up of single-walled carbon nanotube, borax and polyvinyl alcohol (Cai et al. 2017). It proved that the combination of matrix material and active conductive material could enhance the sensitivity and irritation response behavior of hydrogel (Bae et al. 2016; Hao et al. 2018). Liao and co-workers successfully developed a freeze-resistant (-40 $\left.{ }^{\circ} \mathrm{C}\right)$, self-healing and conductive nanocomposite hydrogel by the method of soaking MXene nanocomposite hydrogel in ethylene glycol solution to replace the water molecules (Liao et al. 2019). It illuminated that it was feasible to convert hydrogel to organic gel to enhance its frost resistance, inevitably decreasing its biocompatibility. 
It is significant to design a low-cost conductive hydrogel with simple process, strong hydrophilicity, high strength and marvelous frost resistance. Flexible sensors usually consist of stretchable matrixes and conductive materials. Polymers or copolymers were commonly used to fabricate stretchable matrix materials, but they are not easy to degrade (Li et al. 2020). Biocompatible materials should not negatively affect the human body. Biomass materials (Chen et al. 2020; Wang et al. 2020) such as cellulose had the characteristics of degradability, good biocompatibility, low price and easy availability (Klemm et al. 2005; Klemm et al. 2011; Roh et al. 2015; Zhou et al. 2017; Yin et al. 2020). Nanocelluloses usually provided reinforcement in the materials of films, hydrogels, aerogels, 3D printing ink and poams. This kind of ecofriendly, lightweight material is suitable for structural, (opto) electronic, photonic, and medical applications (Yang et al. 2020). 2,2,6,6-tetramethylpiperidinyl-1-oxyl (TEMPO) was used as the oxidant to catalyze oxidation wood pulp to obtain TEMPO-oxidized cellulose nanofibrils (TOCNs) with carboxyl groups on the surface which could be individually dispersed in water (Isogai et al. 2011; Isogai et al. 2018; Yang et al. 2018). TOCNs possessed high aspect ratio, high modulus, and satisfactory thermal stability (Xu et al. 2019, 2020; Zhan et al. 2019). TOCN hydrogel was regarded as an appropriate matrix material, which was flexible, stretchable and corrosion-resistant (Xie et al. 2020). The active materials employed to enhance the conductivity of flexible sensors commonly included ion conductors (Ding et al. 2017), carbon-based nanomaterials (Xu et al. 2020), metal-based nanomaterials (Son et al. 2018) and conductive polymers (Han et al. 2017). Carbon-based nanomaterials such as carbon nanotubes (CNTs) and graphene were widely reported. However, it has been a challenge for researchers to fabricate high purity and good dispersion carbon-based nanomaterials. The activating treatment of carbon-based nanomaterials was also quite complicated, which made CNTs suffer from large resistance. Metal-based nanomaterials with high properties such as silver nanowires tended to be expensive. Therefore, it is necessary to seek cheaper active materials that were easier to disperse. Morelle and co-workers conducted research on coordinating hard polyacrylamide-alginate double network hydrogel with calcium chloride aqueous solution. The obtained hydrogel could be cooled to $-57^{\circ} \mathrm{C}$ without freezing (Morelle et al. 2018). Doping metal ions with hydrogels was a simple and efficient method to obtain conductive hydrogels (Zhao et al. 2017; Pan et al. 2020; Wu et al. 2019). In addition, the doping of metal ions could lower the freezing point of the hydrogel, so that the hydrogel had antifreezing performance.

In our work, TOCN hydrogels were crosslinked under hydrochloric acid atmosphere. The threedimensional network structure of TOCN hydrogels led to the high porosity and water content. TOCN hydrogels were immersed in different ionic aqueous solutions and then assembled into ionotronic skin (Iskin) sensor devices. $\mathrm{LiCl}, \mathrm{CaCl}_{2}$ and $\mathrm{KCl}$ were used as active materials to enhance the conductivity of the hydrogels. The sensing performance and the conductivity of each hydrogel were studied and compared.

\section{Experimental}

\section{Materials}


Softwood bleached kraft pulp (SBKP) provided by Nippon Paper Industries in Japan was used to prepare TEMPO-oxidized cellulose nanofibrils. The TEMPO oxidant was purchased from Sigma Aldrich Corporation (Saint Louis, USA). $\mathrm{NaClO}$ was obtained from Aladdin (Shanghai, China). $\mathrm{LiCl}, \mathrm{CaCl}_{2}, \mathrm{KCl}, \mathrm{HCl}$ and other chemicals were analytical grade, bought from Sinopharm Chemical Reagent Co. Ltd (China) and operated strictly as received.

\section{Preparation of aqueous TOCN dispersion and ionic solution}

TEMPO-oxidized cellulose (TOC) was prepared by the TEMPO/ $\mathrm{NaBr} / \mathrm{NaClO}$ system with $\mathrm{NaClO}$ content of $5.0 \mathrm{mmol} \mathrm{g}{ }^{-1}$-cellulose in aqueous solution at $\mathrm{pH} 10$ followed by addition of $1 \mathrm{wt} \% \mathrm{NaBH}_{4}$ to convert the small amounts of C6-aldehydes and C2/C3-ketones to be complete hydroxyl groups following the previously reported method (Shi et al. 2015; Takaichi et al. 2014). The obtained TOC was washed with deionized water until neutral. Then, TOC slurry aqueous solution was prepared with a mass fraction of $0.5 \mathrm{wt} \%$. The TOC slurry solution was put into a high-pressure homogenizer to prepare a TOCN dispersion. Since the surface of TOC contained a large amount of carboxylate groups, it was easy to obtain a transparent and uniform TOCN dispersion under the action of high-pressure mechanical shearing.

$\mathrm{LiCl}$ was dissolved in water to prepare aqueous solution with $\mathrm{LiCl}$ concentration of $2,4,8$, and $16 \mathrm{~mol} \mathrm{~L}^{-1}$. $4 \mathrm{~mol} \mathrm{~L}^{-1} \mathrm{CaCl}_{2}$ and $\mathrm{KCl}$ aqueous solution were also obtained as above.

\section{Preparation of ionic conductive TOCN hydrogel I-skin}

The beaker containing $10 \mathrm{ml} 36 \%$ hydrochloric acid and the 24-well plate containing $48 \mathrm{~g} \mathrm{TOCN}$ dispersion were sealed in the same sealed bag to prepare TOCN hydrogels. TOCN hydrogels were crosslinked under hydrochloric acid atmosphere for $48 \mathrm{~h}$, followed by washing and preservation in the deionized water. These hydrogels were then immersed in $\mathrm{LiCl}, \mathrm{CaCl}_{2}$, and $\mathrm{KCl}$ aqueous solutions with various concentrations, respectively, to endow TOCN hydrogels with ionic conductive properties. The hydrogels were immersed into the ion solutions for $48 \mathrm{~h}$, and the ion solutions were refreshed every $6 \mathrm{~h}$. The process and possible mechanism were shown in Fig. 1. The large amount of metal ions throughout the cellulose nanofibrils could be utilized to prepare conductive hydrogel I-skin.

The hydrogels had the properties of electrical conductivity and sensing property after being immersed in metal ions solutions. Tin foil was used as an electrode material respectively, and was attached to both ends of the hydrogel bulks when the voltage was applied. Each experiment was repeated three times to ensure the accuracy of the data. The hydrogels crosslinked with hydrochloric acid were named as $\mathrm{H}^{+}$TOCN. The hydrogels immersed in metal ions were named as $\mathrm{Li}^{+}-\mathrm{TOCN}, \mathrm{Ca}^{2+}-\mathrm{TOCN}, \mathrm{K}^{+}-\mathrm{TOCN}$ respectively. The hydrogels obtained by immersion in lithium ions solutions with $\mathrm{LiCl}$ concentration of 2 , 4, 8, and $16 \mathrm{~mol} \mathrm{~L}^{-1}$ were named as $2 \mathrm{Li}^{+}-\mathrm{TOCN}, 4 \mathrm{Li}^{+}-\mathrm{TOCN}, 8 \mathrm{Li}^{+}-\mathrm{TOCN}$, and $16 \mathrm{Li}^{+}-\mathrm{TOCN}$, respectively. The hydrogel obtained by immersion in $4 \mathrm{~mol} \mathrm{~L}^{-1} \mathrm{CaCl}_{2}$ solutions was named as $4 \mathrm{Ca}^{2+}-\mathrm{TOCN}$, and immersion in $4 \mathrm{~mol} \mathrm{~L}^{-1} \mathrm{KCl}$ solution was named as $4 \mathrm{~K}^{+}-\mathrm{TOCN}$. 


\section{Analysis}

Scanning electron microscope (SEM) (Hitachi S-4800, Japan) with an accelerating voltage of $5 \mathrm{kV}$ was used to observe the cross-sectional morphology of hydrogels. The hydrogels used for the SEM test were solvent-exchanged with ethanol and $t$-butanol, fractured to expose the cross section in liquid nitrogen and then vacuum freeze-dried. Fourier transform infrared (FTIR) spectra was analyzed by a FTIR spectrometer (Nicolet 6700, USA) in the wavenumber ranging from 4000 to $500 \mathrm{~cm}^{-1}$. The freeze-dried samples of unoxidized cellulose, TOCNs and $\mathrm{Ca}^{2+}{ }_{-}$TOCN hydrogels were cut into powders, and then mixed with $\mathrm{KBr}$ for measurement. Four-point probe instrument (ST2258C) was utilized for the conductivity data of the $12 \times 12$ $\mathrm{mm}$ square samples with a thickness between 80-90 $\mu \mathrm{m}$. Five parallel samples were chosen to ensure the accuracy of the conductivity data with corresponding test parameters. The hydrogels with a height of $10 \mathrm{~mm}$ and a diameter of $10 \mathrm{~mm}$ were prepared for testing the mechanical properties by an electromechanical universal testing machine (MTS Exceed E44, China), following the standard of GB/T 1040:2006. The parameters were set by the initial grip distance of $10 \mathrm{~mm}$ and speed of $1 \mathrm{~mm} \mathrm{~min}-1$ while 5 specimens were selected for parallel experiments. Sensor performance was represented by the electrochemical workstation with type of $\mathrm{CHI} 660 \mathrm{E}$ (China) to measure the l-t curve in real time with an applied voltage of $2 \mathrm{~V}$ DC. When the metal wire was connected, tin foil was used as electrode material and the hydrogel was applied equal pressure to observe the current change.

\section{Results And Discussion}

\section{Structures of ionic conductive TOCN hydrogels}

The SEM images in Fig. 2(a) showed the cross-sectional morphologies of $\mathrm{Li}^{+}-\mathrm{TOCN}$, which were proved to exhibit the three-dimensional network structure. The interior of hydrogels presented a three-dimensional highly porous network structure formed by interconnected nanofibers. The pores were between several nanometers and tens of nanometers in size, and the overall three-dimensional network structure showed in Fig. 2(a) was relatively uniform. The nanofibers demonstrated a large surface area, which made it easier for metal ions to enter the cellulose network, thus providing conditions for improving the conductivity of the hydrogels. The excellent internal network structure benefited to the easier shuttle of conductive ions inside the hydrogels, thus giving the hydrogel excellent sensing performance.

The unoxidized cellulose, TOCNs, $\mathrm{H}^{+}-\mathrm{TOCN}, \mathrm{Ca}^{2+}-\mathrm{TOCN}$ were analyzed by infrared spectroscopy. The FTIR spectra were shown in Fig. 2(b). It could be seen from the Fig. 2(b) that the four samples had relatively obvious absorption bands near $3400 \mathrm{~cm}^{-1}$, which were attributed to the stretching vibration absorption band of hydroxyl group on cellulose. The strong band corresponding to the hydrogen-bonded hydroxyl of unoxidized cellulose was observed at $3356 \mathrm{~cm}^{-1}$. The bands at $2890 \mathrm{~cm}^{-1}$ of each sample corresponded to the stretching vibration of the $\mathrm{C}-\mathrm{H}$ bond on cellulose; the bands at $1020 \mathrm{~cm}^{-1}$ represented the stretching vibration of $\mathrm{C}-\mathrm{O}$ on the backbone of cellulose macromolecules (Yue et al. 2021). Compared with the unoxidized cellulose, the spectra of TOCNs and $\mathrm{Ca}^{2+}$-TOCN exhibited asymmetric -OCO- 
stretching bands at 1607 and $1604 \mathrm{~cm}^{-1}$, respectively. In the spectra of unoxidized cellulose and $\mathrm{H}^{+}$TOCN, the bands of $1645 \mathrm{~cm}^{-1}$ and $1636 \mathrm{~cm}^{-1}$ were attributed to the absorption of the water which was not completely dried in the nanocellulose (Yue et al. 2019; Zheng et al. 2020). In addition, $\mathrm{H}^{+}-\mathrm{TOCN}$ exhibited a new characteristic absorption band at $1724 \mathrm{~cm}^{-1}$ which was attributed to the vibration absorption band of - $\mathrm{COOH}$. Under the circumstances of hydrochloric acid cross-linking, part of the free sodium ions in the nanocellulose network were replaced by the hydrogen ions in hydrochloric acid, facilitating the $\mathrm{H}^{+}$in the solution and the $\mathrm{COO}^{-}$on the cellulose macromolecular skeleton combined to form a carboxylic acid. The band at $1724 \mathrm{~cm}^{-1}$ disappeared after the replacement of $\mathrm{Ca}^{2+}$ ion solution, indicating that the structure of carboxylic acid - $\mathrm{COOH}$ was broken and the hydrogen ion on the carboxylic acid was replaced by part of the calcium ion. Calcium ions and carboxylate groups were re-complexed and coordinated, which enabled the network structure of hydrogels to be more stable while improving its mechanical properties (Fig. S1) and electrical conductivity.

Figure 2 (a) Cross-sectional SEM image of $4 \mathrm{Li}^{+}-\mathrm{TOCN}$, (b) FTIR spectra of $\mathrm{Ca}^{2+}-\mathrm{TOCN}, \mathrm{H}^{+}-\mathrm{TOCN}, \mathrm{TOCN}$ dispersion, and unoxidized cellulose

\section{Mechanical properties of ionic conductive TOCN hydrogels}

The compressive stress-strain curves of the TOCN hydrogels which were immersed in various ions aqueous solutions were shown in Fig. $\mathrm{S} 1 . \mathrm{Li}^{+}, \mathrm{Ca}^{2+}$ and $\mathrm{K}^{+}$were introduced to prepare the metal ionimmersed conductive hydrogels. As shown in Fig. S1(a) and Table 1, there was no obvious difference among $\mathrm{H}^{+}-\mathrm{TOCN}, 4 \mathrm{~K}^{+}-\mathrm{TOCN}, 4 \mathrm{Ca}^{2+}-\mathrm{TOCN}$, and $4 \mathrm{Li}^{+}-\mathrm{TOCN}$ hydrogels. The compressive strength of $4 \mathrm{Ca}^{2+}$ TOCN was $54 \mathrm{kPa}$, and the stain was $67 \%$. Compressive stress-strain curves of $\mathrm{Li}^{+}-\mathrm{TOCN}$ hydrogels with different $\mathrm{Li}^{+}$concentrations were shown in Fig. S1(b). The Fig. S1(b) indicated that the mechanical properties of the $\mathrm{Li}^{+}$-TOCN hydrogels did not decrease compared with the $\mathrm{H}^{+}-\mathrm{TOCN}$ hydrogel blank sample. On the contrary, the mechanical properties of the hydrogels were improved to a certain degree after the replacement of $\mathrm{Li}^{+}$solutions. $8 \mathrm{Li}^{+}-\mathrm{TOCN}$ exhibited best among the samples which presented outstanding compression strength of $72.4 \mathrm{kPa}$. Lithium ions can enhance the interaction of water molecules in hydrogels (Ge et al. 2020). In addition, the compressive strain of the nanocellulose conductive hydrogels with ultrahigh water content and high porosity prepared by this method was about $60 \%$. Its satisfactory mechanical properties profoundly broadened the application prospects of the conductive hydrogel I-skin.

\section{Sensing properties of ionic conductive TOCN hydrogels}

Figure 3 presented the schematic design of ionic hydrogels. The cellulose nanofibers network possesses negative charges due to the carboxyl groups on the nanofibers. Cellulose nanofiber network also has strong hydrogen bonds, which provides the basis for the excellent mechanical properties of hydrogels. After the hydrogels were immersed in metal ions solutions, metal ions were locked in hydrogel network, and electrostatic interaction formed between carboxyl groups in the TOCN networks and metal cations. Meanwhile, part of the hydrogen bonds between the cellulose molecules were broken by the doping ions. 
The doping of metal ions improved the electrical conductivity of the hydrogels. As shown in Fig. 3(c), the metal cations and anions in TOCN network could transport freely under applied voltage. Under the condition of external force, the migration ability of various cations was the primary reason for the current variation of the assembled I-skin sensor.

The $1-t$ curves of the TOCN hydrogels immersed in $4 \mathrm{~mol} \mathrm{~L}^{-1} \mathrm{Ca}^{2+}, \mathrm{K}^{+}$, and $\mathrm{Li}^{+}$solutions were shown in Fig. 4, which reflected the sensitivity of each sample. The larger fluctuation range of the output signal of the sample was corresponded to more excellent sensing performance under the equal slight pressure. The hydrogels became deformed when pressed, and the resistance changed accordingly. The hydrogels were pressed with the equal force repeatedly to obtain the corresponding current curves with time after connecting the power. The strain-sensitive performance of the hydrogels was attributed to the fact that electronically charged ions could penetrate in the network. Compressive stress changed the electrical resistance of the hydrogel. The sensing performance of $\mathrm{H}^{+}$-TOCN hydrogels was lower than the $\mathrm{Li}^{+} / \mathrm{Ca}^{2+} / \mathrm{K}^{+}$-immersed hydrogels. Under the condition of exerting the same stress, the current fluctuation range of $\mathrm{H}^{+}-\mathrm{TOCN}$ was 3.7-4.5 $\mathrm{AA}$ in Fig. $\mathrm{S} 1$, the current fluctuation range of $4 \mathrm{Li}^{+}-\mathrm{TOCN}$ was approximately 5.3-6.6 $\mu \mathrm{A}$ in Fig. 4(a), current of $4 \mathrm{Ca}^{2+}-\mathrm{TOCN}$ fluctuated in the range of $4.9-5.5 \mu \mathrm{A}$ in Fig. 4(b) and $4 \mathrm{~K}^{+}-\mathrm{TOCN}$ fluctuated within 4.2-4.7 $\mu \mathrm{A}$ in Fig. 4(c). The $4 \mathrm{Li}^{+}-\mathrm{TOCN}$ hydrogel exhibited the widest range of current response according to Fig. 4(d), which was as high as $23 \%$ and about twice as much as those of $4 \mathrm{~K}^{+}-\mathrm{TOCN}$ and $4 \mathrm{Ca}^{2+}-\mathrm{TOCN}$. As shown in Fig. $4(\mathrm{e})$, the conductivity of $4 \mathrm{Li}^{+}-\mathrm{TOCN}$ was about $4.36 \times 10^{-4} \mathrm{~S} \mathrm{~cm}^{-1}$, while $4 \mathrm{Ca}^{2+}-\mathrm{TOCN}$ of $1.61 \times 10^{-4} \mathrm{~S} \mathrm{~cm}^{-1}$ and $4 \mathrm{~K}^{+}-\mathrm{TOCN}$ of $1.29 \times 10^{-4} \mathrm{~S} \mathrm{~cm}^{-1}$ were lower. Comparing the radii of these three ions $\left(\mathrm{Li}^{+} \square \mathrm{Ca}^{2+} \square \mathrm{K}^{+}\right)$, which demonstrated that the smaller the radius, the better for ions to penetrate the holes in the three-dimensional network structure of nanocellulose hydrogels under homogeneous force. These identically figured out that diverse conductive ions had conspicuous effect on the sensing performance. Therefore, the sensing performance of $\mathrm{Li}^{+}-$ TOCN was recognized as the optimal.

Figure 4 Sensing properties of nanocellulose hydrogels with different replacing methods. I-t curves of (a) $4 \mathrm{Li}^{+}-\mathrm{TOCN}$. (b) $4 \mathrm{Ca}^{2+}-\mathrm{TOCN}$, and (c) $4 \mathrm{~K}^{+}-\mathrm{TOCN}$. (d) $\triangle / / \mathrm{I}_{0^{-}} \mathrm{t}$ curves of $4 \mathrm{Li}^{+}-\mathrm{TOCN}, 4 \mathrm{Ca}^{2+}-\mathrm{TOCN}$, and $4 \mathrm{~K}^{+}-$ TOCN. (e) The conductivity of $4 \mathrm{Li}^{+}-\mathrm{TOCN}, 4 \mathrm{Ca}^{2+}-\mathrm{TOCN}, 4 \mathrm{~K}^{+}$- and TOCN

It was significant to explore the influence of lithium ions with different concentrations on the sensing performance of the hydrogels, because $\mathrm{Li}^{+}-\mathrm{TOCN}$ performed the best among these three ions. The sensor performance of $\mathrm{Li}^{+}$-immersed hydrogels with the solution concentration of $2,4,8$, and $16 \mathrm{~mol} \mathrm{~L}^{-1}$ were shown in Fig. 5 and Fig. 6. $\mathrm{Li}^{+}-\mathrm{TOCN}$ hydrogels with different concentrations showed regularity when applied the equal pressure, and the higher concentrations of lithium ions could make the better initial current value and conductivity. The current fluctuation range of $2 \mathrm{Li}^{+}-\mathrm{TOCN}, 4 \mathrm{Li}^{+}-\mathrm{TOCN}, 8 \mathrm{Li}^{+}-\mathrm{TOCN}$, and $16 \mathrm{Li}^{+}-\mathrm{TOCN}$ were $4.2-5.2 \mu \mathrm{A}, 5.3-6.6 \mu \mathrm{A}, 5.8-7.1 \mu \mathrm{A}$, and 7.1-8.3 $\mu \mathrm{A}$ respectively. This phenomenon confirmed that increasing the concentration of the immersed solution was capable of augmenting the charged ions inside the hydrogels, impelling it easier for the ions to form a current under the action of 
voltage. Immersing the hydrogels in the ionic solutions to enhance the conductivity, the stable localization of metal ions was promoted through electrostatic action based on the negative charge of TOCN hydrogel network. Simultaneously, metal ions shuttled and transported in the hydrogel network freely under an applied voltage, leading to the hydrogels a higher ion conductivity and excellent responsiveness.

Figure 5 Sensing properties of TOCN hydrogels immersed by different concentrations $\mathrm{LiCl}$ aqueous solutions. I-t curves of (a) 2Li+-TOCN, (b) 4Li+-TOCN, (c) $8 \mathrm{Li}^{+}-\mathrm{TOCN}$, and (d) $16 \mathrm{Li}^{+}-\mathrm{TOCN}$

Fig. 6(a) shows the responsiveness of $\mathrm{Li}^{+}-\mathrm{TOCN}$. The current fluctuation range value would not continuously increase as different ion concentrations under the same pressure but reached the maximum rate of current change $\left(\Delta / / I_{0}=23.8 \%\right)$ at $4 \mathrm{Li}^{+}-\mathrm{TOCN}$, which illustrated that the effect of increasing ion concentrations on the sensing performance of hydrogels was limited. The conductivity of $\mathrm{Li}^{+}-\mathrm{TOCN}$ behaved better when the concentration of the ions increased, and $16 \mathrm{Li}^{+}-\mathrm{TOCN}$ met the highest conductivity of $5.21 \mathrm{~S} \mathrm{~cm}^{-1}$ in Fig. 6(c). Futhermore, different pressure was applied to $4 \mathrm{Li}^{+}-\mathrm{TOCN}$ for the purpose of demonstrating the maximum current change caused by the ion-immersed hydrogels.

Figure 6(b) presented the fantastic current change of $127 \%$ under a larger force. The rate of current change fluctuated between $5 \%-127 \%$. This suggested that hydrogels were highly sensitive to the changes in pressure.

Figure 6 Sensing properties of $\mathrm{Li}^{+}-\mathrm{TOCN}$. (a) $\Delta / / I_{0}$-t curves of $2 \mathrm{Li}^{+}-\mathrm{TOCN}, 4 \mathrm{Li}^{+}-\mathrm{TOCN}, 8 \mathrm{Li}^{+}-\mathrm{TOCN}$, and $16 \mathrm{Li}^{+}-\mathrm{TOCN}$. (b) $\triangle / / \mathrm{I}_{0}$-t curves of $4 \mathrm{Li}^{+}-\mathrm{TOCN}$ under different pressure. (c) The conductivity of $2 \mathrm{Li}^{+}-\mathrm{TOCN}$, $4 \mathrm{Li}^{+}-\mathrm{TOCN}, 8 \mathrm{Li}^{+}-\mathrm{TOCN}$, and $16 \mathrm{Li}^{+}-\mathrm{TOCN}$

\section{Antifreezing performance of ionic conductive TOCN hydrogels}

The $\mathrm{Ca}^{2+}{ }^{-} \mathrm{TOCN}$ hydrogel was selected for the freezing-resistance experiment due to its satisfactory sensing performance and human-friendly. Figure 7(a) indicated that there was no significant decrease at low temperature, and the current fluctuation range of $4 \mathrm{Ca}^{2+}-\mathrm{TOCN}$ hydrogels at $-30^{\circ} \mathrm{C}$ was similar $4.9-5.4$ $\mu \mathrm{A}$. Figure $4(\mathrm{~b})$ revealed that the current fluctuation range of $4 \mathrm{Ca}^{2+}-\mathrm{TOCN}$ hydrogels at $25^{\circ} \mathrm{C}$ were $4.9-5.5$ $\mu \mathrm{A} . \Delta / / I_{0}$-t curves of $4 \mathrm{Ca}^{2+}-\mathrm{TOCN}$ hydrogels in Fig. $7(\mathrm{~b})$ behaved similarly at different temperature, which demonstrated the antifreezing performance of $4 \mathrm{Ca}^{2+}-\mathrm{TOCN}$ hydrogels. The high conductivity at low temperatures might due to the fact that the salt solutions successfully displaced the water inside the hydrogels, and the addition of salt lowered the hydrogel's freezing point. Due to the presence of metal ions, the hydrogels possessed considerable frost resistance. The mechanical property had no obvious change at $-30^{\circ} \mathrm{C}$ as shown in Fig. $7(\mathrm{c})$, demonstrating that the $4 \mathrm{Ca}^{2+}-\mathrm{TOCN}$ hydrogels would not freeze at $-30^{\circ} \mathrm{C}$. The conductivity hydrogels were capable of detecting body signals such as the bending of fingers in Fig. 7(d), and the detected current changes increased with the increase of finger bending angle. Figure 7(e) displayed a picture of a transparent and intact 4Ca ${ }^{2+}$-TOCN hydrogel, which lighted a small 
LED under applied voltage at $25^{\circ} \mathrm{C}$ and $-30^{\circ} \mathrm{C}$. Compared with the $4 \mathrm{Ca}^{2+}-\mathrm{TOCN}$ at room temperature, the morphology of the hydrogels at $-30^{\circ} \mathrm{C}$ was almost the same. Figure $7(\mathrm{e})$ showed the electrical conductivity of the $4 \mathrm{Ca}^{2+}-\mathrm{TOCN}$ at $-30^{\circ} \mathrm{C}$ almost same as the $4 \mathrm{Ca}^{2+}-\mathrm{TOCN}$ at $25^{\circ} \mathrm{C}$, and Fig. $7(\mathrm{f})$ was the schematic diagram of lighting LEDs. These results confirmed that the hydrogels immersed in calcium chloride solution could maintain equal sensing performance, electrical conductivity and mechanical properties at $-30^{\circ} \mathrm{C}$. The prominent performance immensely can broaden the application range of this ionconductivity hydrogels, confirming that it could be utilized in low temperature environments.

Figure 7 Low temperature resistance of $4 \mathrm{Ca}^{2+}-\mathrm{TOCN}$. (a) I-t curves of $4 \mathrm{Ca}^{2+}-\mathrm{TOCN}$ at $-30^{\circ} \mathrm{C}$. (b) $\triangle \mathrm{I} / \mathrm{I}_{0} \mathrm{O}^{-\mathrm{t}}$ curves of $4 \mathrm{Ca}^{2+}-\mathrm{TOCN}$ at $25^{\circ} \mathrm{C}$ and $-30^{\circ} \mathrm{C}$. (c) Compressive stress-strain curves of $4 \mathrm{Ca}^{2+}-\mathrm{TOCN}$ at $25^{\circ} \mathrm{C}$ and $-30^{\circ} \mathrm{C}$. (d) $\triangle \mathrm{I} / \mathrm{I}_{0}$-t curves of $4 \mathrm{Ca}^{2+}-\mathrm{TOCN}$ with the finger benting. (e) LED s were lighted under a series circuit of the DC power supply. (f) Schematic diagram of lighting LEDs

\section{Conclusions}

The convenient and low-cost method of adding metal ions to the TOCN hydrogels to obtain the antifreezing, high-conductivity, and transparent piezoresistive l-skin was employed in this work. The SEM images indicated that the nanocellulose hydrogels still maintained a three-dimensional network structure with high porosity after immersion. The hydrogels doped with metal ions exhibited better strength and toughness. The mechanical properties of ion-immersed TOCN hydrogels did not decrease compared with $\mathrm{H}^{+}$-TOCN hydrogels. Under the same concentration of the $\mathrm{Li}^{+} / \mathrm{Ca}^{2+} / \mathrm{K}^{+}$-immersed hydrogels, the conductivity of $\mathrm{Li}^{+}$was the best, followed by $\mathrm{Ca}^{2+}$. As the $\mathrm{Li}^{+}$concentration reached $16 \mathrm{~mol} \mathrm{~L}^{-1}$, the conductivity was up to $5.21 \times 10^{-4} \mathrm{~S} \mathrm{~cm}^{-1}$. The current response changes of $4 \mathrm{Li}^{+}-\mathrm{TOCN}, 4 \mathrm{Ca}^{2+}-\mathrm{TOCN}$, and $4 \mathrm{~K}^{+}$-TOCN were $23.7 \%, 12.5 \%$, and $12 \%$ respectively under equal pressure. Increasing the concentration of the ions could enhance the sensing performance to a certain extent, and $4 \mathrm{Li}^{+}-\mathrm{TOCN}$ hydrogels was optimal. The sensitivity test demonstrated that $4 \mathrm{Li}^{+}-\mathrm{TOCN}$ hydrogels presented the considerable responsiveness of $127 \%$. The low-temperature tests indeed successfully proved that the calcium ionimmersed hydrogels still maintained high conductivity, acceptable mechanical properties and sensing performance at $-30^{\circ} \mathrm{C}$, which provided possibilities for low-temperature applications in wearable electronics, artificial intelligence, and medical health.

\section{Declarations}

\section{Acknowledgements}

This work was supported by the National Natural Science Foundation of China (No. 21704079 and 51703177), the Fundamental Research Funds for the Central Universities (WUT: 2020IB030) and Key laboratory of Processing and Quality Evaluation Technology of Green Plastics of China National Light Industry council, Beijing Technology and Business University, Beijing 100048, China (No.

PQETGP2019007). 


\section{Compliance with Ethical Standards}

Conflict of Interest: The authors declare that they have no conflict of interest.

Human and animal rights: The study was approved by the Ethics Committee of Wuhan University of Technology. All procedures performed in studies involving human were in accordance with the ethical standards of the institution or practice at which the studies were conducted.

Informed consent: Informed consent was obtained from all individual participants included in the study.

\section{References}

Amjadi M, Kyung KU, Park I, Sitti M (2016) Stretchable, skin-mountable, and wearable strain sensors and their potential applications: a review. Adv Funct Mater 26(11):1678-1698. https://doi.org/10.1002/adf m.2015047 55

Bae GY, Pak SW, Kim D, Lee G, Kim DH, Chung Y et al (2016) Linearly and highly pressure-sensitive electronic skin based on a bioinspired hierarchical structural array. Adv Mater 28(26):5300-5306. https://doi.org/1 0.1002/adma.201600408

Cai GF, Wang JX, Qian K, Chen J, Li S, Lee PS (2017) Extremely stretchable strain sensors based on conductive self-healing dynamic cross-links hydrogels for human-motion detection. Adv Sci 4(2):1600190. https://doi.o rg/10.1002/advs.201600190

Chen H, Li X, Yu W, Wang J, Shi Z, Xiong C, Yang Q (2020) Chitin/MoS 2 nanosheet dielectric composite films with significantly enhanced discharge energy density and efficiency. Biomacromolecules 21:29292937. https://doi.org/10.1021/acs.biomac.0c00732

Darabi MA, Khosrozadeh A, Mbeleck R, Liu Y, Chang Q, Jiang J et al (2017) Skin-inspired multifunctional autonomic-intrinsic conductive self-healing hydrogels with pressure sensitivity, stretchability, and 3D printab ility. Adv Mater 29(31):1700533. https://doi.org/10.1002/adma.201700533

Ding Y, Zhang J, Chang L, Zhang X, Liu H, Jiang L (2017) Preparation of high-performance ionogels with excellent transparency, good mechanical strength, and high conductivity. Adv Mater 29(47):1704253. https:/ /doi.org/10.1002/adma.201704253

Dong K, Peng X, Wang ZL (2020) Fiber/fabric-based piezoelectric and triboelectric nanogenerators for flexible/stretchable and wearable electronics and artificial intelligence. Adv Mater 32(5):1902549. https://doi. org/10.1002/adma.201902549

Ge W, Cao S, Yang Y, Rojas OJ, Wang X (2020) Nanocellulose/LiCl systems enable conductive and stretchable electrolyte hydrogels with tolerance to dehydration and extreme cold conditions. Chem Eng J. https://doi.org/ 10.1016/j.cej.2020.127306 
Hao B, Mu L, Ma Q, Yang SD, Ma PC (2018) Stretchable and compressible strain sensor based on carbon nanotube foam/polymer nanocomposites with three-dimensional networks. Compos Sci Technol 163:162-170. https://d oi.org/10.1016/j.compscitech.2018.05.017

Huang S, Liu Y, Zhao Y, Ren Z, Guo CF (2018) Flexible electronics: stretchable electrodes and their future. Adv Funct Mater 29(6):1805924. https://doi.org/10.1002/adfm.201805924

Isogai A, Hänninen T, Fujisawa S, Saito T (2018) Catalytic oxidation of cellulose with nitroxyl radicals under aqueous conditions. Prog Polym Sci 86:122-148.

https://doi.org/10.1016/j.progpolymsci.2018.07.007

Isogai A, Saito T, Fukuzumi H (2011) TEMPO-oxidized cellulose nanofibers. Nanoscale 3(1):71-85. https://doi.or g/10.1039/CONR00583E

Kim J, Campbell AS, de Avila BE, Wang J (2019) Wearable biosensors for healthcare monitoring. Nat Biotechnol 37(4):389-406. http://doi.org/10.1038/s41587-019-0045-y

Klemm D, Heublein B, Fink HP, Bohn A (2005) Cellulose: fascinating biopolymer and sustainable raw material. Angew Chem Int Ed Engl 44(22):3358-3393. https://www.ncbi.nlm.nih.gov/pubmed/15861454

Klemm D, Kramer F, Moritz S, Lindstrom T, Ankerfors M, Gray D et al (2011) Nanocelluloses: a new family of nature-based materials. Angew Chem Int Ed Engl 50(24):5438-5466.

https://www.ncbi.nlm.nih.gov/pubmed/ 21598362

Kwon D, Lee TI, Shim J, Ryu S, Kim MS, Kim S et al (2016) Highly sensitive, flexible, and wearable pressure sensor based on a giant piezocapacitive effect of three-dimensional microporous elastomeric dielectric Layer. Acs Appl Mater Inter 8(26):16922-16931.

https://www.ncbi.nlm.nih.gov/pubmed/27286001

Li SN, Li B, Yu ZR, Gong LX, Xia QQ, Feng Y et al (2020) Chitosan in-situ grafted magnetite nanoparticles toward mechanically robust and electrically conductive ionic-covalent nanocomposite hydrogels with sensitive strain-responsive resistance. Compos Sci and Technol 195:108173.

https://doi.org/10.1016/j.compsc itech.2020.108173

Liao H, Guo X, Wan P, Yu G (2019) Conductive MXene nanocomposite organohydrogel for flexible, healable, low-temperature tolerant strain sensors. Adv Funct Mater 29(39): 1904507. https://doi.org/10.1002/adfm.201904507

Morelle XP, Illeperuma WR, Tian K, Bai R, Suo Z, Vlassak JJ (2018) Highly stretchable and tough hydrogels below water freezing temperature. Adv Mater 30(35): 1801541. https://doi.org/10.1002/adma.201801541.

Pan X, Wang Q, He P, Liu K, Ni Y, Chen L et al (2020) A bionic tactile plastic hydrogel-based electronic skin constructed by a nerve-like nanonetwork combining stretchable, compliant, and self-healing properties. 
Chem Engin J 379(34):17279-17830. https://doi.org/10.1039/D0TA04741D

Roh E, Hwang BU, Kim D, Kim BY, Lee NE (2015) Stretchable, transparent, ultrasensitive, and patchable strain sensor for human-machine interfaces comprising a nanohybrid of carbon nanotubes and conductive elastomers. Acs nano 9(6):6252-6261. https://doi.org/10.1021/acsnano.5b01613

Shi ZQ, Yang QL, Ono Y, Funahashi R, Saito T, Isogai A (2015) Creation of a new material stream from Japanese cedar resources to cellulose nanofibrils. React Funct Polym 95:19-24.

https://doi.org/10.1016/j.reactfun ctpolym.2015.08.005

Son D, Kang J, Vardoulis O, Kim Y, Matsuhisa N, Oh JY et al (2018) An integrated self-healable electronic skin system fabricated via dynamic reconstruction of a nanostructured conducting network. Nat Nanotechnol 13(57):1057-1065. https://www.ncbi.nlm.nih.gov/pubmed/30127474

Song Y, Shi Z, Hu G-H, Xiong C, Isogai A, Yang Q (2020) Recent advances of cellulose-based piezoelectric and triboelectric nanogenerators for energy harvesting: A review. J Mater Chem A. https://doi.org/10.1039/D0TA 08642H

Sun JY, Keplinger C, Whitesides GM, Suo Z (2014) Ionic skin. Adv Mater 26(45): 7608-7614. https://www.ncbi.nl m.nih.gov/pubmed/25355528

Takaichi S, Saito T, Tanaka R, Isogai A (2014) Improvement of nanodispersibility of oven-dried TEMPOoxidized celluloses in water. Cellulose 21(6):4093-4103. https://doi.org/10.1007/s10570-014-0444-7

Wan YB, Wang Y, Guo CF (2017) Recent progresses on flexible tactile sensors. Mater Today Phys 1:61-73. https:/ /doi.org/10.1016/j.mtphys.2017.06.002

Wang J, Chen H, Li X, Zhang C, Yu W, Zhou L, Yang Q et al (2020) Flexible dielectric film with high energy density based on chitin/boron nitride nanosheets. Chem Eng J 383:123147.

https://doi.org/10.1016/j.cej.2019.123147

Wang XW, Gu Y, Xiong ZP, Cui Z, Zhang T (2014) Silk-molded flexible, ultrasensitive, and highly stable electronic skin for monitoring human physiological signals. Adv Mater 26(9):1336-1342. https://doi.org/10.1 002/adma.201304248

Wu J, Wu Z, Lu X, Han S, Yang BR, Gui X et al (2019) Ultrastretchable and stable strain sensors based on antifreezing and self-healing ionic organohydrogels for human motion monitoring. ACS Appl Mater Interfaces 11(9):9405-9414. https:// doi.org/10.1021/acsami.8b20267

Xie Y, Xu H, He X, Hu Y, Zhu E et al (2020) Flexible electronic skin sensor based on regenerated cellulose/carbon nanotube composite films. Cellulose 27(17):10199-10211.

https://doi.org/10.1007/s10570-020-03496-w 
Xu H, Liu Y, Xie Y, Zhu E, Shi Z, Yang Q et al (2019) Doubly cross-linked nanocellulose hydrogels with excellent mechanical properties. Cellulose 26(16):8645-8654. https://doi.org/10.1007/s10570-01902689-2

Xu H, Xie Y, Zhu E, Liu Y, Shi Z, Xiong C et al (2020) Supertough and ultrasensitive flexible electronic skin based on nanocellulose/sulfonated carbon nanotube hydrogel films. J Mater Chem A 8(13): 6311-6318. https://doi.org/10.1039/d0ta00158a

Yan CY, Wang JX, Kang WB, Cui MQ, Wang X, Foo CY et al (2014) Highly stretchable piezoresistive graphene-nanocellulose nanopaper for strain sensors. Adv Mater 26(13):2022-2027. https://doi.org/10.1002/adma.2013 04742

Yang JC, Mun J, Kwon SY, Park S, Bao Z, Park S (2019) Electronic skin: recent progress and future prospects for skin-attachable devices for health monitoring, robotics, and prosthetics. Adv Mater 31(48):1904765. https://d oi.org/10.1002/adma.201904765

Yang J, Xie H, Chen H, Shi Z, Wu T, Yang Q, Xiong C (2018) Cellulose nanofibril/boron nitride nanosheet composites with enhanced energy density and thermal stability by interfibrillar cross-linking through $\mathrm{Ca}^{2+}$. J Mater Chem A 6(4):1403-1411. https://doi.org/10.1039/C7TA08188J

Yang XP, Biswas SK, Han JQ et al (2020) Surface and Interface Engineering for Nanocellulosic Advanced Materials. Adv Mater. https://onlinelibrary.wiley.com/doi/10.1002/adma.202002264

Yin Y, Zhang C, Yu W, Kang G, Yang Q, Shi Z et al (2020) Transparent and flexible cellulose dielectric films with high breakdown strength and energy density. Energy Storage Mater 26:105-111. https://doi.org/10. 1016/j.ensm.2019.12.034

Yue YY, Gu J, Han JQ et al (2021) Effects of cellulose/salicylaldehyde thiosemicarbazone complexes on PVA based hydrogels: Portable, reusable, and high-precision luminescence sensing of $\mathrm{Cu}^{2+}$. J Hazard Mater 401:123798. https://doi.org/10.1016/j.jhazmat.2020.123798

Yue YY, Wang XH, Han JQ et al (2019) Effects of nanocellulose on sodium alginate/polyacrylamide hydrogel: Mechanical properties and adsorption-desorption capacities. Carbohyd Polym 206:289-301. https://doi.org/1 0.1016/j.carbpol.2018.10.105

Zhan Y, Xiong CX, Yang JW, Shi ZQ, Yang QL (2019) Flexible cellulose nanofibril/pristine graphene nanocompo site films with high electrical conductivity. Compos Part A-Appl S 119:119-126. https://doi.org/1 0.1016/j.compositesa.2019.01.029

Zhao S, Li J, Cao D, Zhang G, Li J, Li K et al (2017) Recent advancements in flexible and stretchable electrodes for electromechanical sensors: strategies, materials, and features. ACS Appl Mater Interfaces 9(14):12147-12164. https://www.ncbi.nlm.nih.gov/pubmed/28281337 
Zheng CX, Lu KY, Lu Y et al (2020) A stretchable, self-healing conductive hydrogels based on nanocellulose supported graphene towards wearable monitoring of human motion. Carbohyd Polym 250:116905. https://doi. org/10.1016/j.carbpol.2020.116905

\section{Figures}

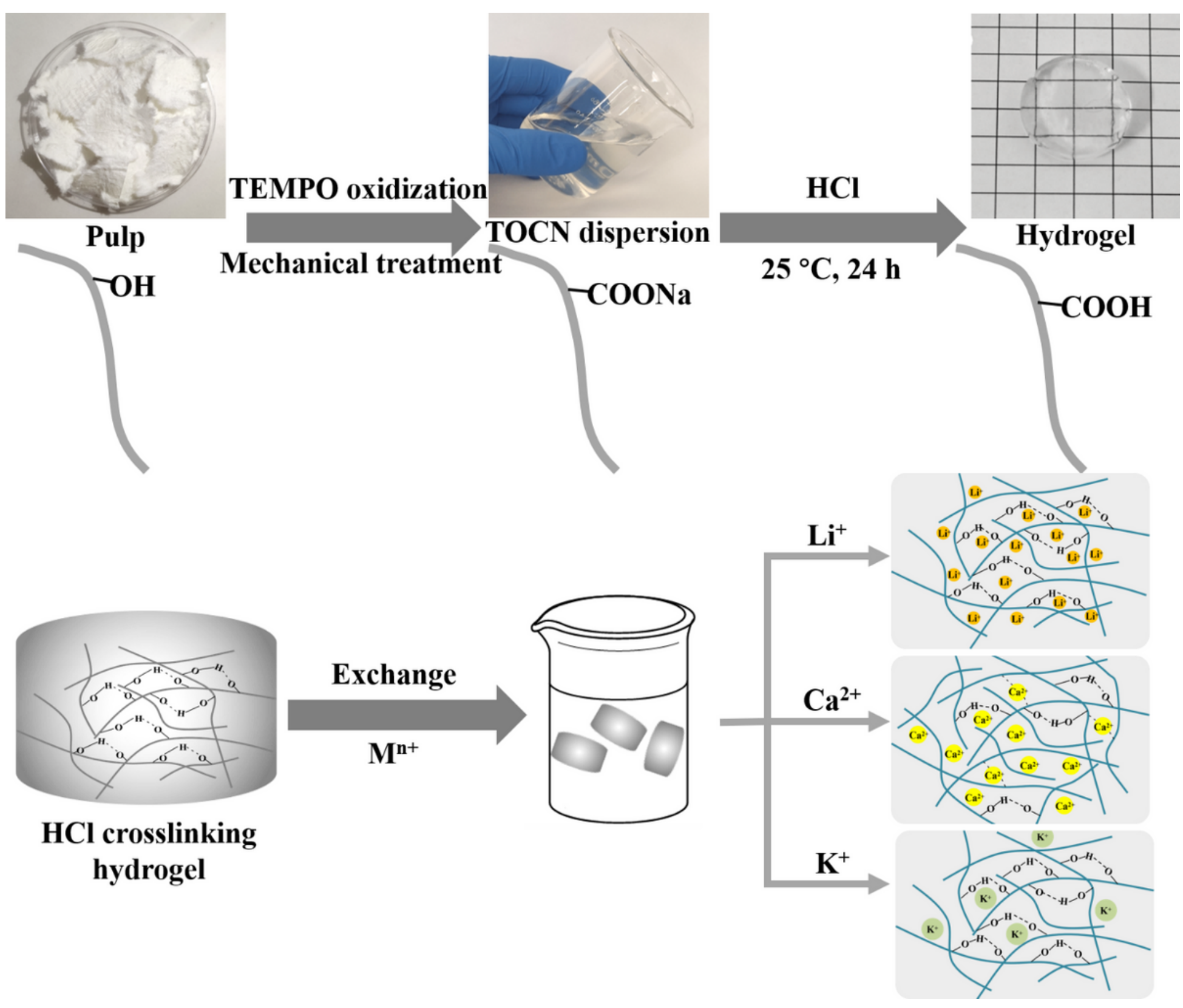

Figure 1

Schematic diagram of preparation of the TOCN, Li+-TOCN, Ca2+-TOCN, and K+-TOCN hydrogels 
a

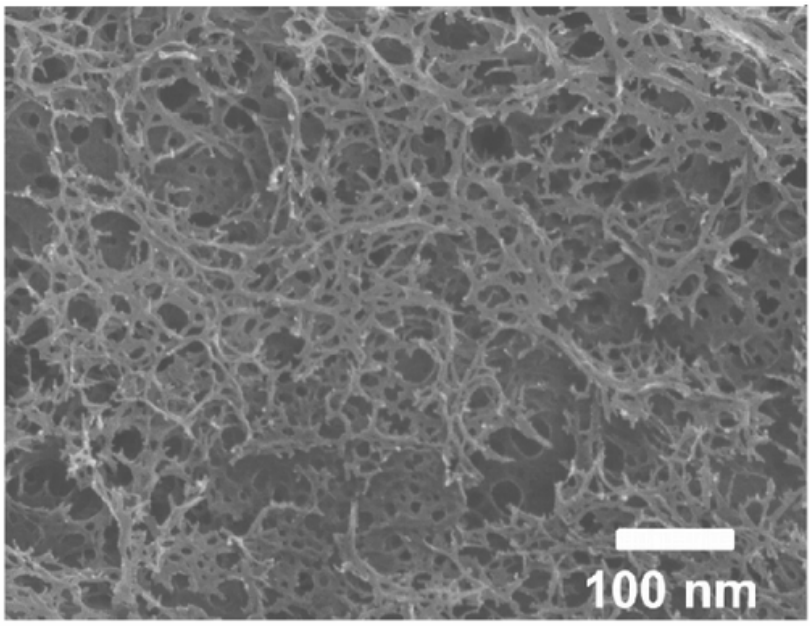

b

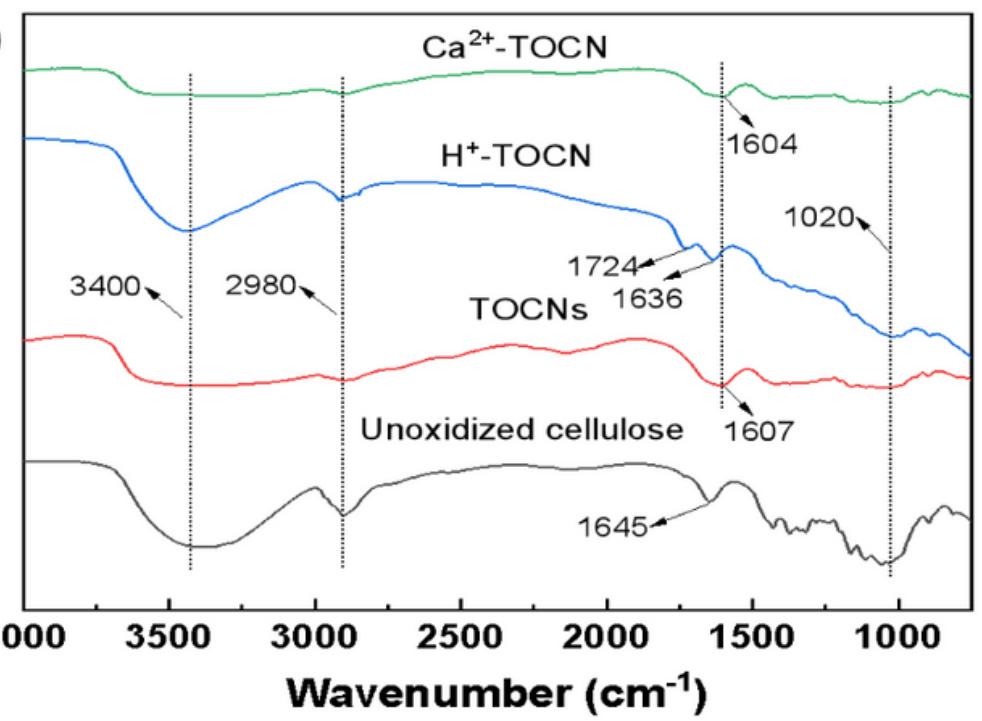

Figure 2

(a) Cross-sectional SEM image of 4Li+-TOCN, (b) FTIR spectra of Ca2+-TOCN, H+-TOCN, TOCN dispersion, and unoxidized cellulose
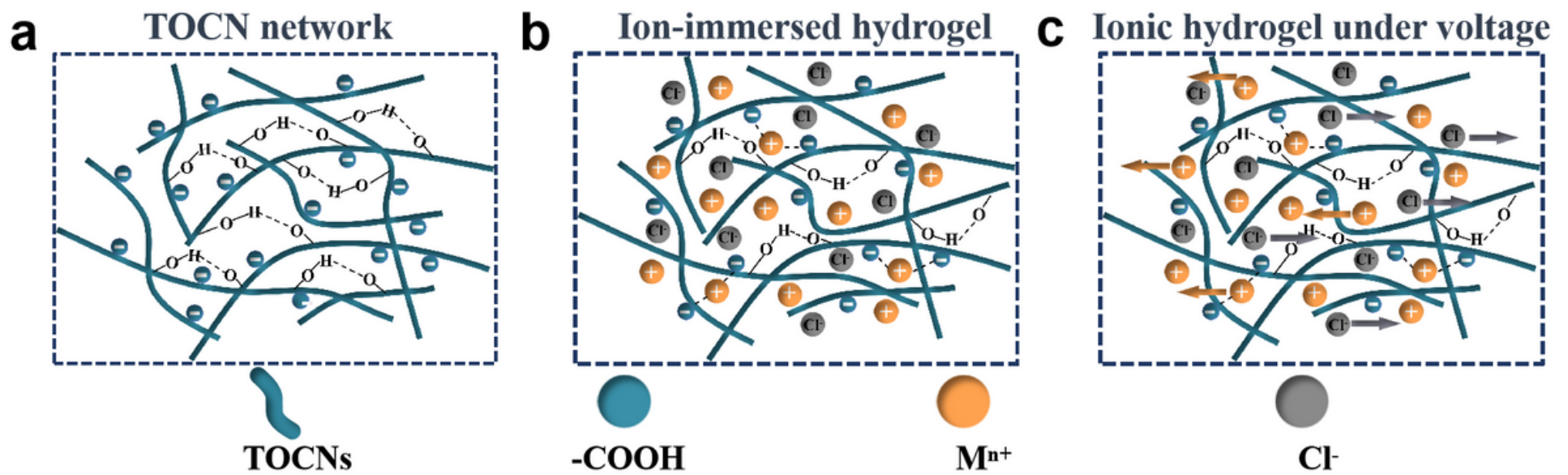

Figure 3

Schematic design of ionic hydrogels: (a) TOCN network, (b) ion-immersed hydrogel, (c) ionic hydrogel under voltage 

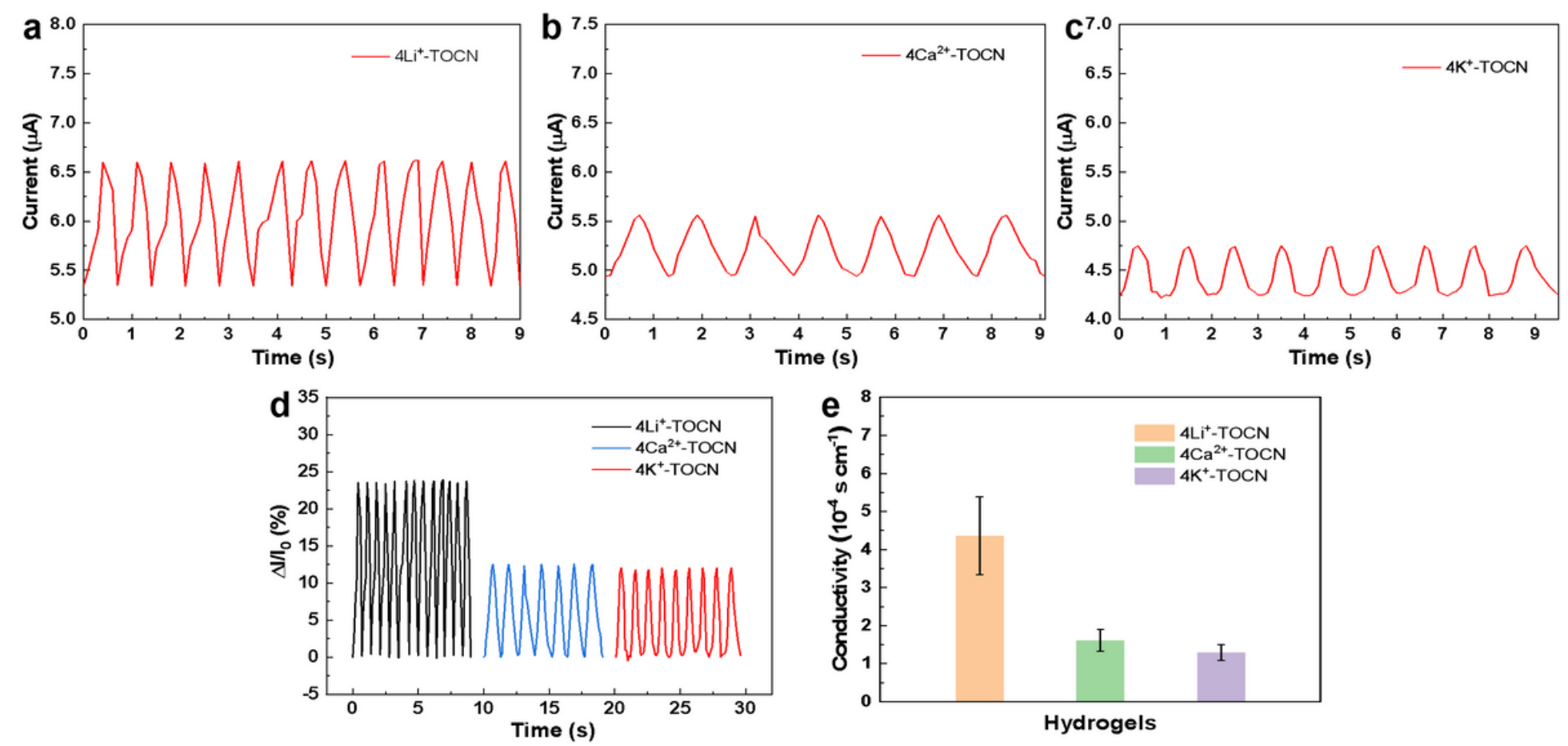

Figure 4

Sensing properties of nanocellulose hydrogels with different replacing methods. I-t curves of (a) 4Li+TOCN. (b) 4Ca2+-TOCN, and (c) 4K+-TOCN. (d) $\triangle \mathrm{I} / \mathrm{I0}$-t curves of 4Li+-TOCN, 4Ca2+-TOCN, and 4K+-TOCN. (e) The conductivity of $4 \mathrm{Li}+-\mathrm{TOCN}, 4 \mathrm{Ca} 2+-\mathrm{TOCN}, 4 \mathrm{~K}+-$ and TOCN 

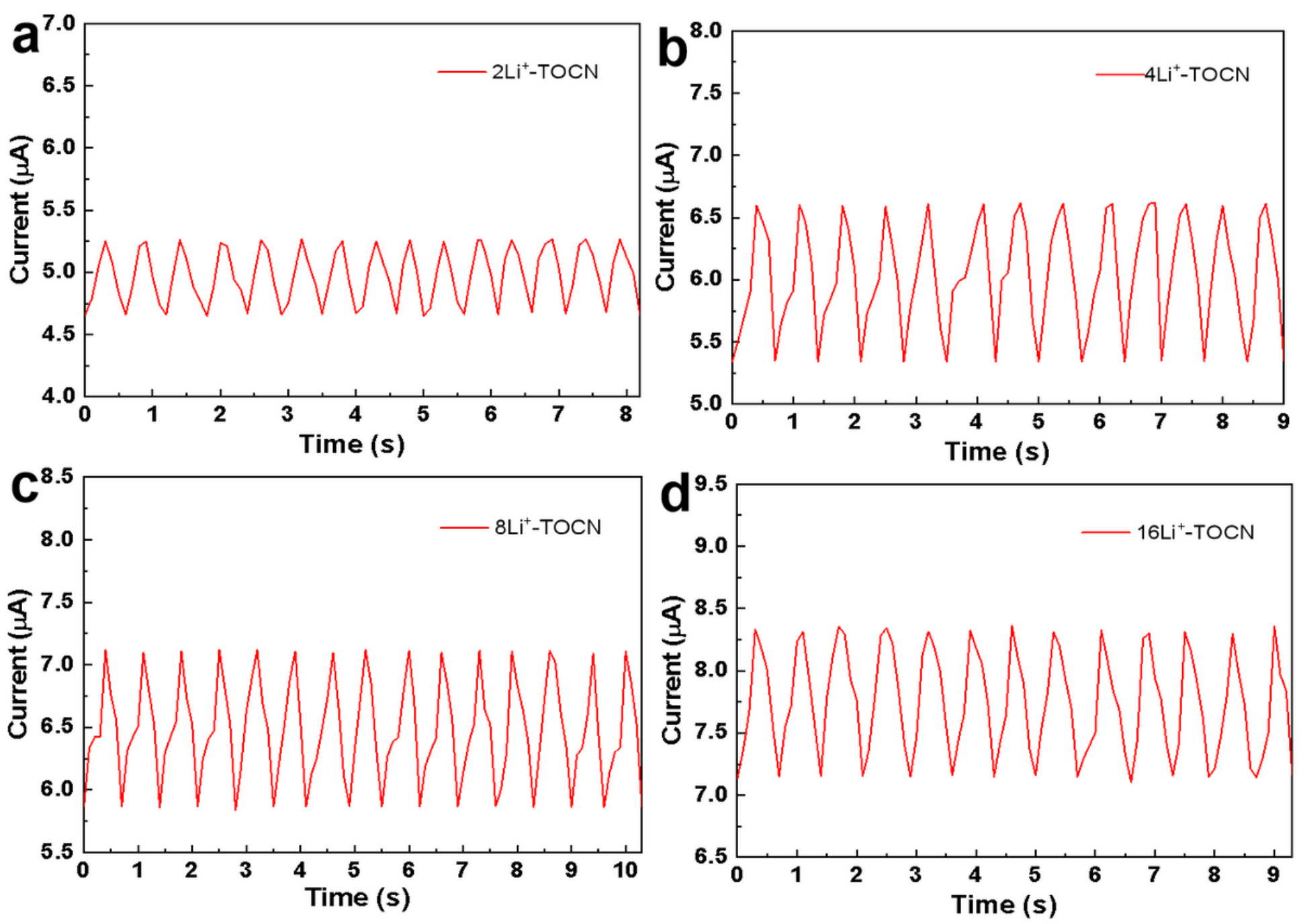

Figure 5

Sensing properties of TOCN hydrogels immersed by different concentrations $\mathrm{LiCl}$ aqueous solutions. I-t curves of (a) 2Li+-TOCN, (b) 4Li+-TOCN, (c) 8Li+-TOCN, and (d) 16Li+-TOCN
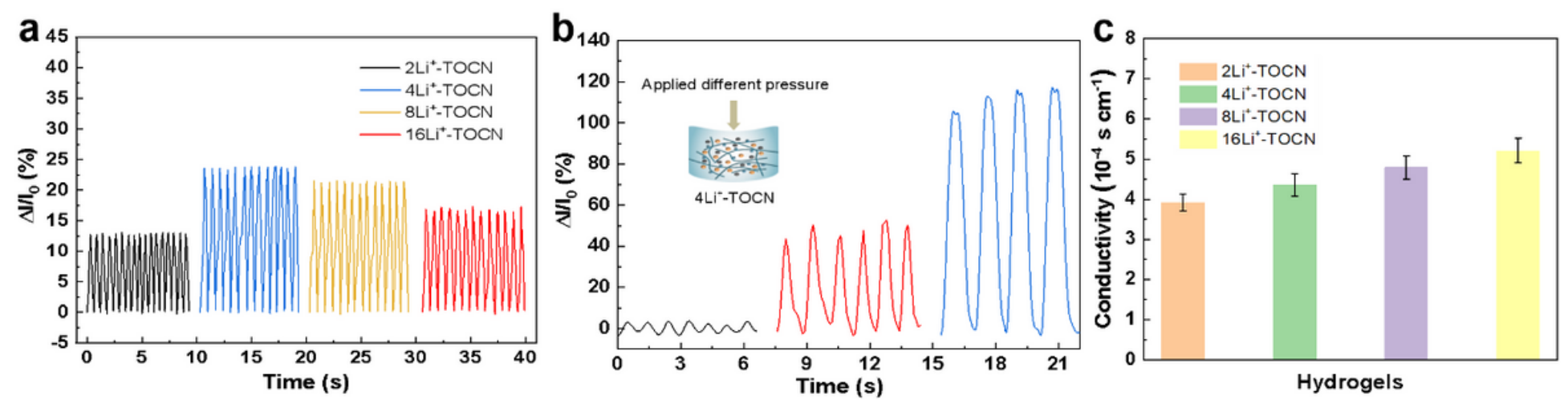

Figure 6

Sensing properties of Li+-TOCN. (a) $\triangle \mathrm{I} / \mathrm{I0-t}$ curves of 2Li+-TOCN, 4Li+-TOCN, 8Li+-TOCN, and 16Li+TOCN. (b) $\triangle \mathrm{I} / \mathrm{IO}$-t curves of $4 \mathrm{Li}+-\mathrm{TOCN}$ under different pressure. (c) The conductivity of 2Li+-TOCN, 4Li+- 
TOCN, 8Li+-TOCN, and 16Li+-TOCN
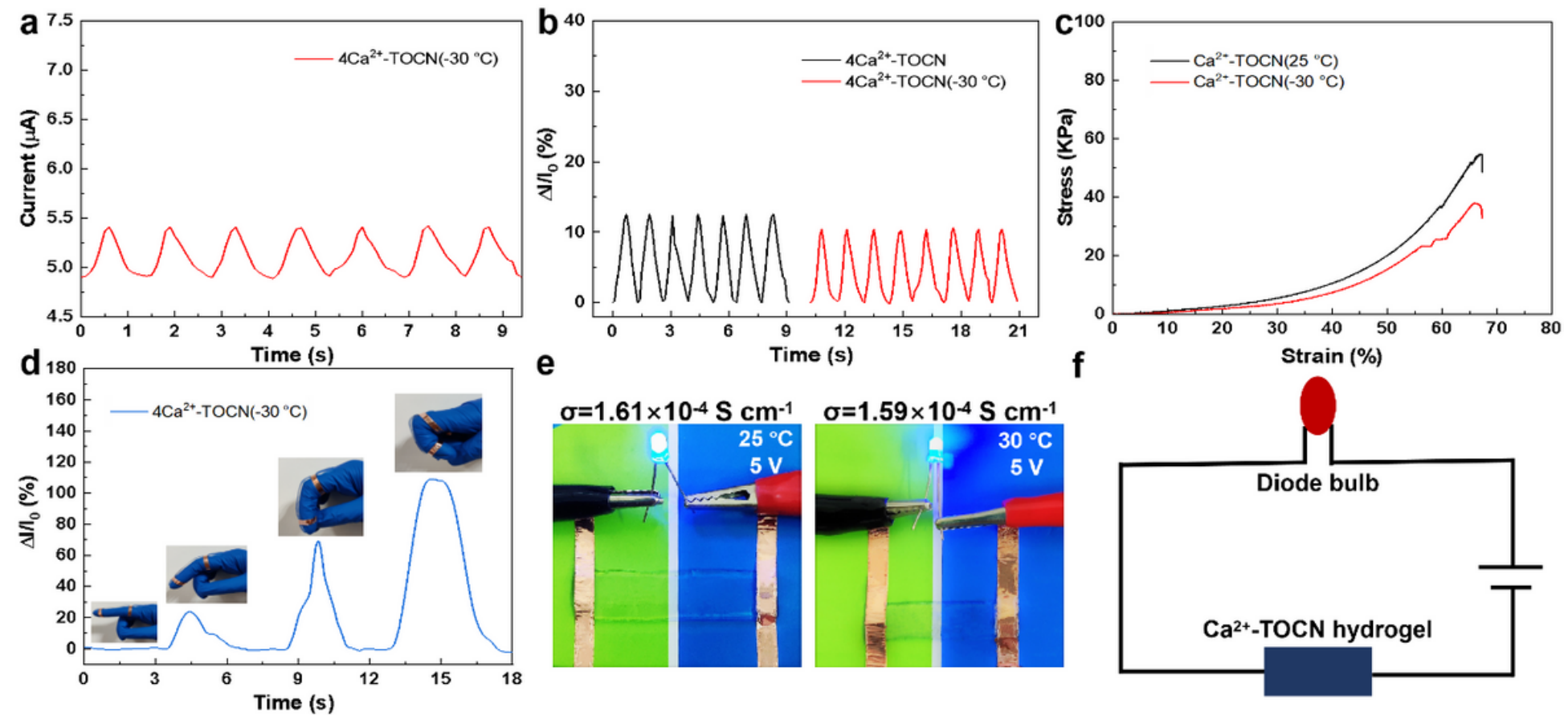

Figure 7

Low temperature resistance of $4 \mathrm{Ca} 2+-\mathrm{TOCN}$. (a) I-t curves of $4 \mathrm{Ca} 2+-\mathrm{TOCN}$ at $-30{ }^{\circ} \mathrm{C}$. (b) $\Delta \mathrm{l} / \mathrm{I0}$-t curves of $4 \mathrm{Ca} 2+-\mathrm{TOCN}$ at $25^{\circ} \mathrm{C}$ and $-30{ }^{\circ} \mathrm{C}$. (c) Compressive stress-strain curves of $4 \mathrm{Ca} 2+-\mathrm{TOCN}$ at $25^{\circ} \mathrm{C}$ and -30 ${ }^{\circ} \mathrm{C}$. (d) $\triangle \mathrm{l} / \mathrm{I0}$-t curves of $4 \mathrm{Ca} 2+-\mathrm{TOCN}$ with the finger benting. (e) LEDs were lighted under a series circuit of the DC power supply. (f) Schematic diagram of lighting LEDs

\section{Supplementary Files}

This is a list of supplementary files associated with this preprint. Click to download.

- Graphicalabstract.png

- Supportinginformation.docx 